\title{
OS OLEIROS E A GESTÃO DA LENHA NAS COZEDURAS REDUTORAS: APROXIMAÇÕES ETNOARQUEOLÓGICAS EM PORTUGAL
}

\author{
ALINE DURAND $^{(1)}$, JACQUES THIRIOT ${ }^{(2)}$, HELDER ABRAÇOS ${ }^{(3)} \&$ LAURENT MAGGIORI $^{(4)}$
}

Resumo:

\begin{abstract}
Na Europa, o abastecimento em lenha que os oleiros utilizam nos fornos de cozedura redutora medieval é mal conhecido. Com efeito, os dados antracológicos são escassos e os textos a esse respeito são muitas das vezes silenciosos. Impõe-se por isso uma abordagem etnoarqueológica, para compreender melhor esta actividade. Uma missão em Portugal, entre 2005 e 2007 teve como objectivo, observar os últimos oleiros artesanais cozendo a sua cerâmica em atmosfera redutora, como na Idade Média. Os inquéritos orais e as observações das cozeduras foram sistematicamente registadas e filmadas. Os dados obtidos completam as observações arqueológicas. Dez ou vinte dias antes da cozedura, os oleiros e seus familiares cortam a lenha com a ajuda de instrumentos agrícolas de uso quotidiano. Não foi observado nenhum corte de lenha em particular. É recolhida lenha de pequena dimensão e calibre $(<2 \mathrm{~cm})$ e não ramos ou troncos, visto que o oleiro deseja um rápido aumento da temperatura nos fornos, antes do seu encerramento. A gestão da lenha e do fogo durante a cozedura, levam a manter as matas limpas. Pela primeira vez, foi dada atenção à observação dos elementos imateriais. O resultado mais importante da pesquisa e que deve ser sublinhado, centrou-se na adaptabilidade dos gestos e na variabilidade das práticas do saber-fazer.
\end{abstract}

Palavras-chave: Lenha, Forno de Oleiro, Cozedura Reductora, Etnoarqueologia, Portugal

\begin{abstract}
Potters and wood management in the reducing cooking: Ethnoarchaeological Approaches in Portugal
In Europe, little is known of the traditional production of black medieval pottery in terms of fuel management Charcoal analysis of this kind of remains is very few and written documentation is often silent. This is why ethnoarchaeological approach plays an important role when attempting to understand this activity. A new research program has been developed in Portugal (2005-2007) where the last European potters produce black ceramic still using the medieval technical process in a reducing atmosphere. Interviews and observations of cooking potteries, systematically recorded by audiovisual means, enrich the archaeological data. Ten or twenty days before using the kiln, fuel is cut with rural and everyday tools and no specific choice has been noted. The potters and their families collect twigs (diameter $<2 \mathrm{~cm}$ ), not big branches or trunks, because they want a very quick rise of temperature into the kiln before closing the door. Thus, the cooking potteries process is successful. This type of fire and fuel management leads to maintain an open landscape. Intangible elements have been observed for the first time. But the major result is the variability of the practices that need to be underline.
\end{abstract}

Keywords: Fuel, Pottery Kiln, Reduction atmosphere, Ethnoarchaeology, Portugal

\section{INTRODUÇÃO}

É uma verdade afirmar que o fogo desempenha um papel privilegiado na organização do trabalho dos oleiros ao nível das cadeias operatórias técnicas.

É igualmente evidente que, durante a cozedura, a gestão pelos oleiros da lenha usada nos fornos, desempenha um papel importante no controlo do lume.

Apesar dos recentes avanços, esta questão encontra-se ainda pouco documentada, em virtude de uma grande ausência de dados documentais e de análises dos carvões de combustão. É o caso das cozeduras redutoras da época medieval, que são, até ao início do século XIV, maioritariamente utilizadas para cozer cerâmica comum negra.

O carvão de lenha artesanal arqueológico carrega consigo estigmas dessas práticas que é preciso interpretar, prestando atenção a parâmetros pouco estudados, a fim de melhor caracterizar a morfologia e o tipo de lenha.

Quando tais análises estiverem disponíveis, como em Saint-Victor-des-Oules (Gard, sul da França) ou em Cabrera d'Anoia (Catalunha) (DURAND 1998 e inédito PY 2001), uma melhor interpretação dos gestos dos oleiros será aferida. A partir desta constatação, uma das pistas apontadas para abordar estas questões é a etnoarqueologia.

Depois dos inquéritos realizados pelos préhistoriadores, ficou demonstrado o interesse por tal metodologia (LEROI-GOURHAN \& BREZILLON 1972, BINFORD 1978). No que toca às olarias, os trabalhos efectuados por A. Gallay junto do povo Dogon (Mali), demonstram a evidência do método (GALlAY \& HUYSECOM 1989). Em arqueologia medieval, esta metodologia data das primeiras

(1) PR Université du Maine Centre de recherches en archéologie, archéosciences histoire UMR 6566 CREAAH CNRS-Université du Maine Email:aline.durand@univ-lemans.fr

${ }^{(2)}$ DR CNRS honoraire Laboratoire d'archéologie médiévale et moderne en Méditerranée UMR 7298 CNRS-Aix-Marseille Université. Email: thiriot@mmsh.univ-aix.fr

${ }^{(3)}$ Câmara Municipal de Tondela Departamento da Educação, Cultura e Desporto. Chefe de Divisão da Cultura. Arquivista. Email: helder.abracos@cm-tondela.pt

(4) AI CNRS Laboratoire d'archéologie médiévale et moderne en Méditerranée UMR 7298 CNRS-Aix-Marseille Université. Email: maggiori@mmsh.univ-ais.fr 
escavações realizadas nas aldeias desertas da Alta Idade Média, em particular em Dracy na Borgonha (BuCAILle \& PeSEz 1980), sendo em França o nascimento desta disciplina. Apesar das pesquisas incidirem sobre as questões do habitat (BAZZANA \& Delaigue 1995; PoISSON 2003a, 2003), o recurso à etnoarqueologia teve pouco desenvolvimento.

No entanto desde 1980 sob o impulso do Laboratoire d'Archéologie Médiévale Méditerranéenne, foram realizados inquéritos etnográficos em Espanha e Portugal, que ajudaram os arqueólogos a interpretar melhor os resultados das escavações das olarias e dos fornos, assim como moinhos e pisões ${ }^{(1)}$. Esta investigação inscreve-se na linha destes inquéritos e beneficiou do trabalho de terreno efectuado desde há trinta anos na Península.

Com efeito, desde 1987, são realizadas em Portugal e no Noroeste de Espanha, pesquisas etnoarqueológicas às olarias e fornos de cozedura redutora. À época, eram as últimas regiões da Europa onde os artesãos ainda coziam de um modo tradicional. Um dos interesses em prosseguir esses estudos era poder observar os oleiros controlarem toda a cadeia operatória técnica do seu trabalho, desde a extracção do barro, aquisição de outras matérias-primas, seu tratamento, até à cozedura das cerâmicas e sua utilização no quotidiano. Deste modo, com o apoio do Fond National pour la Science e do Programme Inter disciplinaire du CNRS Histoire des Savoirs (resp. K. Chemla), no quadro de uma $\mathrm{ACI}^{2}$, foram realizadas em Portugal, entre 2005 e 2007 , três missões de 20 dias cada, junto dos últimos oleiros que coziam cerâmica negra do centro e norte de Portugal (Fig. 1): em Bisalhães (Vila Real) e Vilar de Nantes (Chaves) os oleiros estavam ainda muito activos; em Fazamões (Resende), o último oleiro em actividade à época faleceu durante as missões em curso; em Molelos (Tondela), um único oleiro que já não trabalhava. A necessidade de gravar a memória do saber-fazer era urgente, posto que presentemente já não é possível recolher novas informações. A idade média dos oleiros à época andava pelos 65 anos. Muitos deixam de trabalhar e morrem.

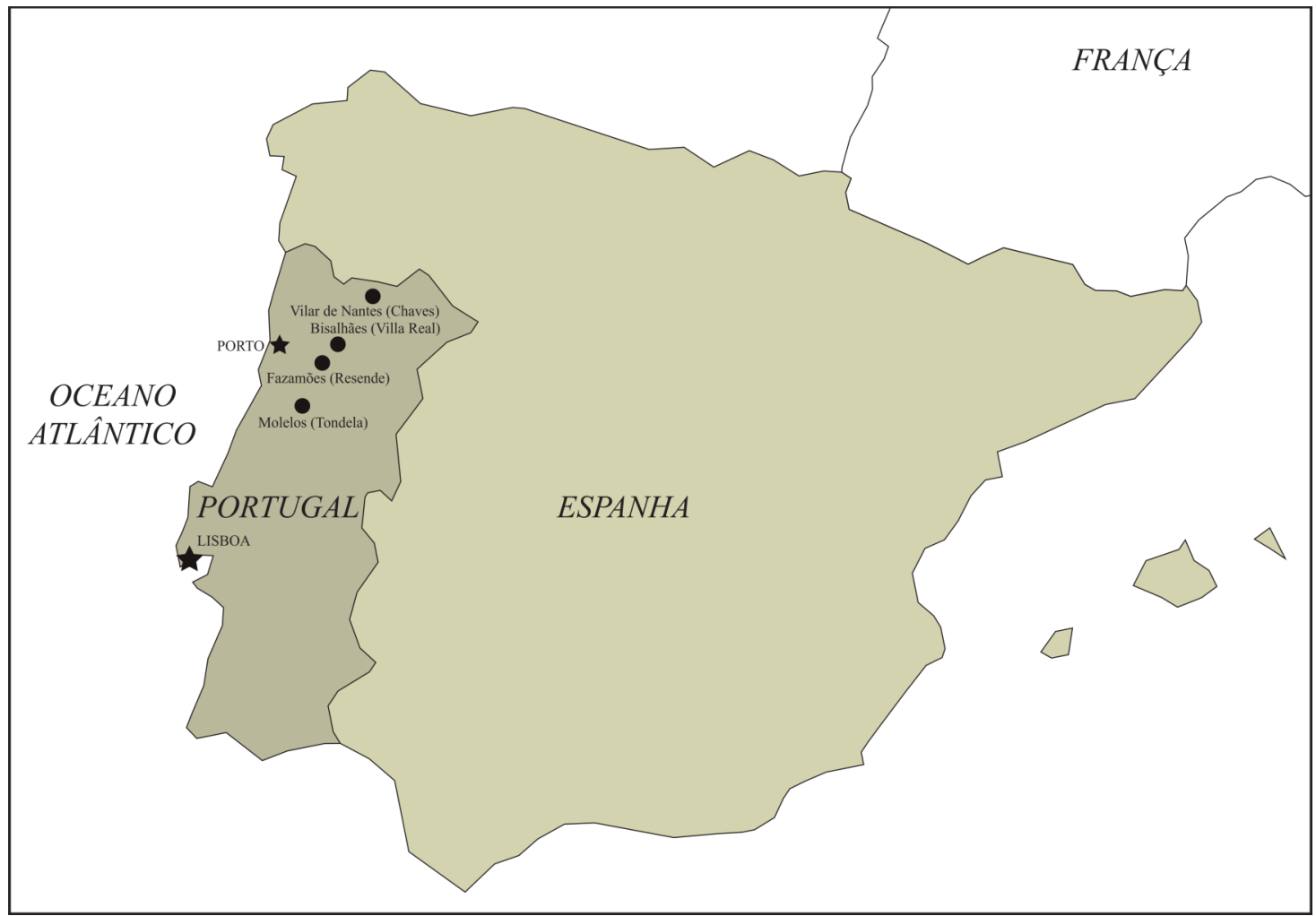

Fig. 1. Localização dos centros produtores tradicionais de louça negra, que foram objecto de inquéritos etnoarqueológicos.

Fig. 1. Localisation of villages where black pottery has been produced using traditional process in a reducing atmosphere and ethnoarchaeological inquiries have been conducted.

\footnotetext{
${ }^{1}$ De 1992 a 2000, realizaram-se em Tondela quatro colóquios internacionais consagrados à cerâmica medieval e pós-medieval, integrando a temática etnoarqueológica, publicados pela Câmara Municipal de Tondela $l$ as Jornadas de cerâmica Medieval e Pós-medieval - métodos e resultados para o seu estudo,

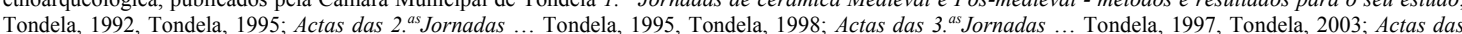
$4 .{ }^{a s}$ Jornadas ... Tondela, 2000, Tondela, 2008).

${ }^{2}$ Action Concerté Incitative du CNRS Culture Scientifique ACI Savoir brûler, savoir gérer le combustible chez les potiers et les mineurs médiévaux méridionaux $\left(11^{\text {ème }}-15^{\text {ème }}\right.$ siècles), responsável A. Durand (Université de Provence-Aix-Marseille I) (2005-2007)
} 


\section{MÉTODO DE INQUÉRITO}

Antes da primeira missão, foi estabelecida a escolha da metodologia a usar nas entrevistas: gravação com perguntas abertas. A grelha de inquérito oral começa com um retrato sumário da vida do oleiro a partir de elementos biográficos (idade, família, percurso profissional) e de informações sobre a transmissão e o exercício da arte de queimar lenha (aprendizagem, prática, transmissão do saber). $\mathrm{O}$ inquérito comporta em seguida perguntas sobre a preparação da lenha: quem adquire (compra ou corte pelo oleiro ou outros), territórios de aquisição (localização geográfica, direitos jurídicos de acesso à propriedade, regularidade no corte, épocas do ano), preço de custo da lenha (tempo despendido, pagamentos), instrumentos usados, tipo de corte e de lenha (variedade, calibre, madeira seca ou verde, utilização das folhas, raízes, cepos, ... época do ano e tempo despendido), modo de transporte e conservação, tratamento (secagem, desbaste ...) e quantidades. Em terceiro lugar, procurou conhecer-se a forma como o oleiro conduz o fogo durante a cozedura. A quarta e última etapa diz respeito à observação da lenha após a pirólise: abertura da fornalha, desenfornar, tratamento do carvão, utilidade e outros fins.

Os inquéritos orais foram sistemática e integralmente registados em formato áudio e filmados por L. Maggiori. As traduções foram asseguradas no terreno por Helder Abraços, arquivista e investigador, com experiência na metodologia etnoarqueológica aplicada às cozeduras redutoras. Os inquéritos foram repetidos com um intervalo de dois anos de forma a poder medir as variações no discurso e nas práticas dos oleiros. Uma vez transcritos e traduzidos integralmente, serão entregues ao museu Terras de Besteiros e postos à disposição dos investigadores. Sete oleiros ainda em actividade foram entrevistados: Sezisnando Ramalho (Bisalhães), Cesário da Rocha Martins (Bisalhães), Querubim Queirós da Rocha (Bisalhães), Manuel Borges (Vilar de Nantes), Arlindo da Silva (Vilar de Nantes), Joaquim Ribeiro Alvéolos (Fazamões) e Graciano Matos Coimbra (Molelos). Estas entrevistas foram completadas por outras de oleiros que já não exerciam a sua arte: António Matos Coimbra (Molelos) e Isildo Carvalho (Bisalhães). Além de outras, realizaram-se um total de onze inquéritos orais e de nove contra-inquéritos, representando mais de trinta horas de entrevistas.

A investigação no terreno consistiu em seguir integralmente as cozeduras realizadas pelos oleiros em actividade, registando e anotando por escrito as observações efectuadas. Uma cobertura fotográfica e audiovisual o mais completa possível dos tempos de cozedura foi sistematicamente realizada por uma câmara profissional. Foram filmadas cinco cozeduras, sendo que duas delas foram realizadas ao mesmo oleiro. Foi também registado, em filme, um corte de lenha.
No final das cozeduras, foram recolhidas amostras de terra e resíduos de carvão para estudo.

\section{AAQUISIÇÃO DA LENHA}

O corte da lenha é feito pelo oleiro com a ajuda da sua mulher, filhos e membros da família. Estes últimos assumem muitas vezes essa tarefa. Enquanto que a produção de cerâmica constitui a principal actividade da aldeia, muitos habitantes, nomeadamente as mulheres em situação de precariedade ou de pobreza, especializavam-se no corte do mato, para assim equilibrar o seu orçamento familiar: em épocas de intensa produção, os oleiros adquirem a estas mulheres pontualmente os molhos de lenha necessários para cozerem a louça. Nas entrevistas realizadas não foi mencionada outra forma de aquisição. Pelo contrário, a pressão sobre as áreas de recolha era fortíssima, o empréstimo era corrente. A devolução fazia-se após as cozeduras.

A lenha utilizada é cortada quase sistematicamente com uma foice, ainda que se utilize pouco a enxada, visto que são os pequenos arbustos das matas que são recolhidos (Fig. 2). A lenha para a cozedura não provém do corte de troncos ou de cavacas, mas de arbustos existentes, sendo que o corte do mato não é feito com os habituais utensílios de lenhador. São pelo contrário utilizados utensílios rurais polivalentes. Certas espécies são referenciadas pelos oleiros (codessos, giestas ...), não sendo objecto de uma escolha deliberada: os arbustos são das espécies mais difusas nas áreas de vegetação aberta, onde os oleiros prioritariamente os cortam. Não é seleccionada nenhuma espécie: os arbustos são cortados sem preferência. Ao contrário, durante a cozedura, os oleiros sublinham a importância de utilizar estes arbustos de pequena dimensão. Não é a espécie o critério determinante, mas a espessura da lenha. Daí a recolha ser feita nas matas e não nos bosques cerrados. Uma vez cortada, a lenha é empilhada em feixes (gavela) atados com fibras vegetais. Estes últimos, os

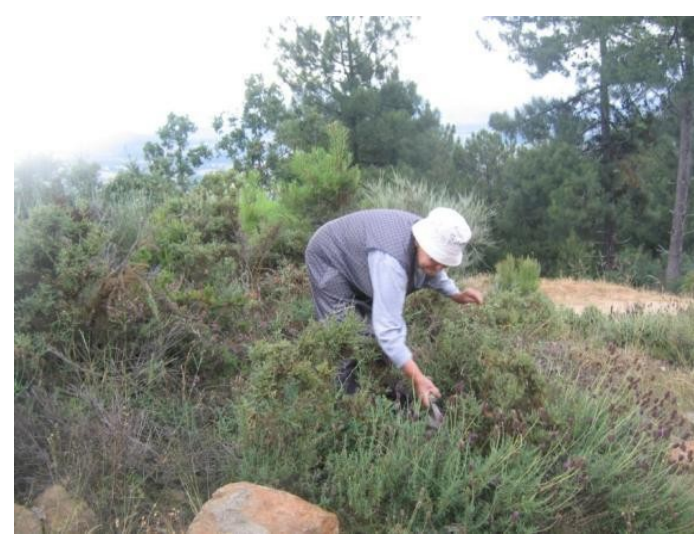

Fig. 2. Corte do mato com a foice. Vilar de Nantes. Fotografia: A. Durand, 19 de Junho de 2006.

Fig. 2. A poter's wife cutting fuel with a sickle. Vilar de Nantes. Ph. A. Durand, June 19th 2006 
arqueólogos dificilmente encontrarão numa escavação (Fig. 3 e 4). Um feixe de lenha pesa entre 5 a $10 \mathrm{Kg}$, enquanto um molho constituído por 4 ou 5 feixes, pesa aproximadamente entre $30 \mathrm{a} 40 \mathrm{Kg}$. Os molhos de lenha são levados às costas ou à cabeça. Quando os locais de recolha são transitáveis, a lenha é transportada numa carroça, puxada por animais. Um molho era pago a 8 escudos $(0,039 €)$, perfazendo uma quantia diária de cerca de 20 a 30 escudos por dois ou três molhos. Uma pequena cozedura consome cerca de 6 molhos de lenha, enquanto uma maior, mais que seis.

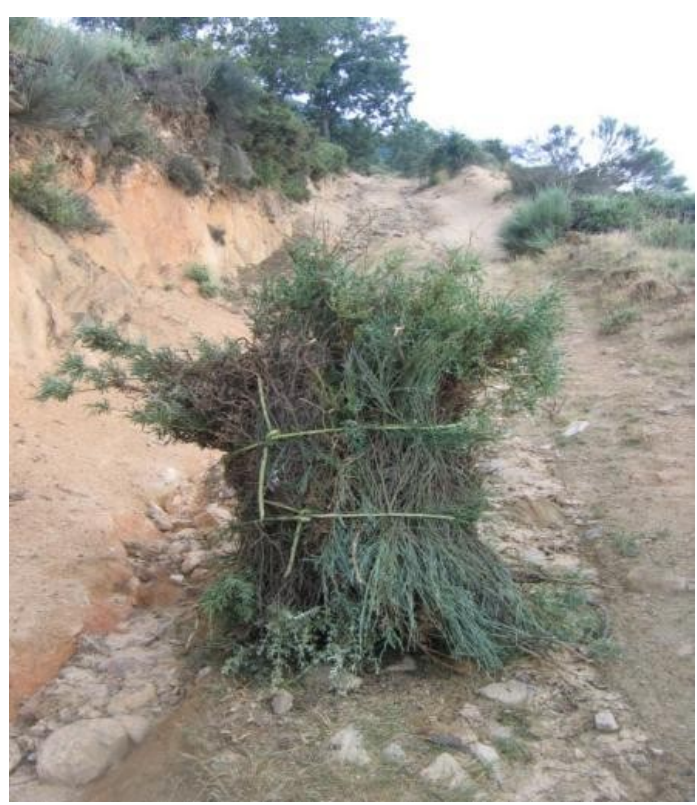

Fig. 3. Enfaixamento do mato num molho atado com fibras vegetais. Vilar de Nantes. Fotografia: A. Durand, 19 de Junho de 2006.

Fig. 3. Bundling pottery fuel using plant ties (Fabaceae). Vilar de Nantes. Ph. A. Durand, June 19th 2006.

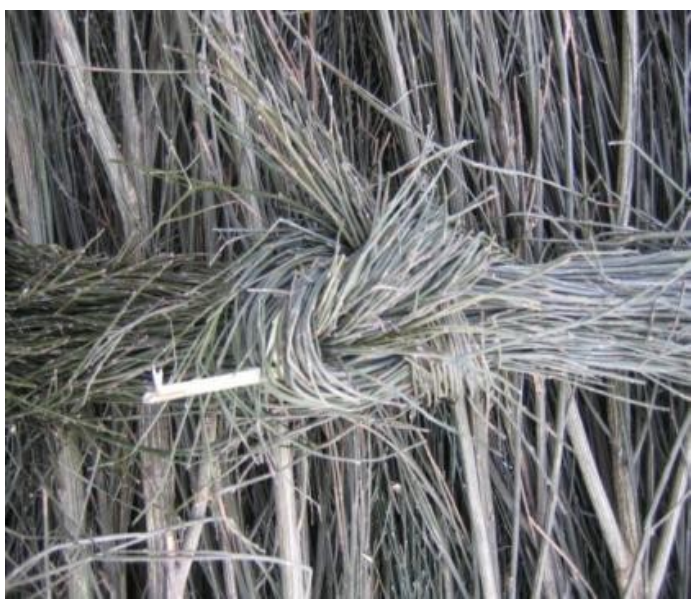

Fig. 4. Pormenor do nó da fibra de atar o mato. M. C. Ferreira. Vilar de Nantes. Fotografia: A. Durand, 19 de Junho de 2006.

Fig. 4. Detail of a knot bundling the pottery fuel composed by twigs and. Vilar de Nantes. Ph. A. Durand, June 19th 2006.
O corte da lenha faz-se em terrenos próximos da aldeia. Quando são distantes, ficam a 3 horas a pé. Daí as áreas de recolha serem locais: ela é apanhada em terrenos que lhes são familiares. Se bem que a lenha seja muitas vezes cortada aqui e acolá sem consentimento, a questão dos direitos de acesso e de recolha é muito fluído: com o acordo dos proprietários, os oleiros apropriam-se das áreas arbustivas a título de direitos de uso, sem se preocuparem com os aspectos jurídicos. O corte da lenha para queimar é feito em função do calendário das cozeduras: não há um período específico, sendo o corte do mato efectuado entre 8-10 dias e 3 semanas antes de cozer. Se são suficientes algumas semanas para terem lenha totalmente seca ou quase, com a influência atlântica, uma semana não é suficiente, pois está ainda verde e cheia de líquidos.

A lenha é guardada quase toda à volta dos fornos, sem organização espacial definida e geralmente colocada ao ar livre. Todavia, quando não se encontra nas proximidades do forno, um alpendre ou um local resguardado, o que é o mais usual, o mato é coberto parcialmente, não na totalidade, com grandes plásticos, visto que o volume armazenado é muito grande (Fig. 5).

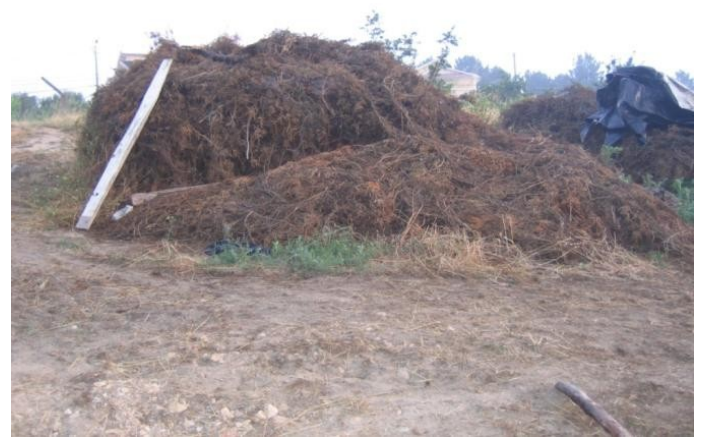

Fig. 5. Depósito de lenha perto do forno de Sezisnando Ramalho. Bisalhães. Fotografia: A. Durand, 24 de Junho de 2006.

Fig. 5. Sezisnando Ramalho's storage fuel around his kiln. Bisalhães. Ph. A. Durand June 24th 2006.

\section{A GESTÃO DO FOGO}

As análises antracológicas efectuadas nos fornos medievais dos oleiros que praticavam a cozedura redutora, revelam a importância do uso de espécies arbustivas usadas durante as cozeduras: é o caso de Saint-Victor-des-Oules e em Cabrera d'Anoia (DURAND 1998 e inédito PY 2001). Quando uma calibragem pode ser efectuada sobre os resíduos arqueológicos, a lenha utilizada terá de ser de pequeno calibre. Sempre que os vestígios se encontram em contexto arqueológico, é possível conhecer a época de corte. Os resultados obtidos sobre os dois grandes sítios arqueológicos de produção de cerâmica negra citados, demonstram que 
não há nenhuma época do ano específica para cortar o mato. Na realidade, os fornos cozem ao longo de todo o ano. As observações feitas em Portugal confirmam os dados arqueológicos: são as espécies arbustivas de pequeno calibre que os oleiros utilizam para alimentarem as fornalhas, sendo o corte do mato feito por encomenda. As razões que levam os oleiros a controlarem o lume durante as cozeduras, podem ser confirmadas pelos inquéritos orais aos artesãos, além das observações.

Com efeito, os oleiros desejam obter um aumento rápido da temperatura nos seus fornos. Esta é mantida a um nível desejado (por volta dos 900-1000 ) para a cerâmica cozer por completo, antes do encerramento total do forno. Para atingir rapidamente as temperaturas elevadas e um determinado tipo de lume, o critério principal é o calibre da lenha, mais do que a qualidade ou o estado dela. Para obter o resultado desejado, é essencial o uso de lenha na fornalha de muito pequeno calibre, como o demonstram os testemunhos dos inquéritos orais e as observações efectuadas.

Assim que o oleiro inicia uma cozedura, acende o lume do forno com o auxílio de um bocado de caruma, com nenhuma hipótese de deixar evidências a nível arqueológico (Fig. 6). É necessário precisar que os fornos são geralmente limpos no seu interior antes da colocação de cerâmicas para uma nova cozedura e não após o desenfornar, detalhe muito interessante para um arqueólogo ou um antracólogo. Após o lume acesso, o oleiro continua a enfornar feixes de caruma ao ritmo de um braçado por minuto e meio durante meia hora, perfazendo um volume de caruma

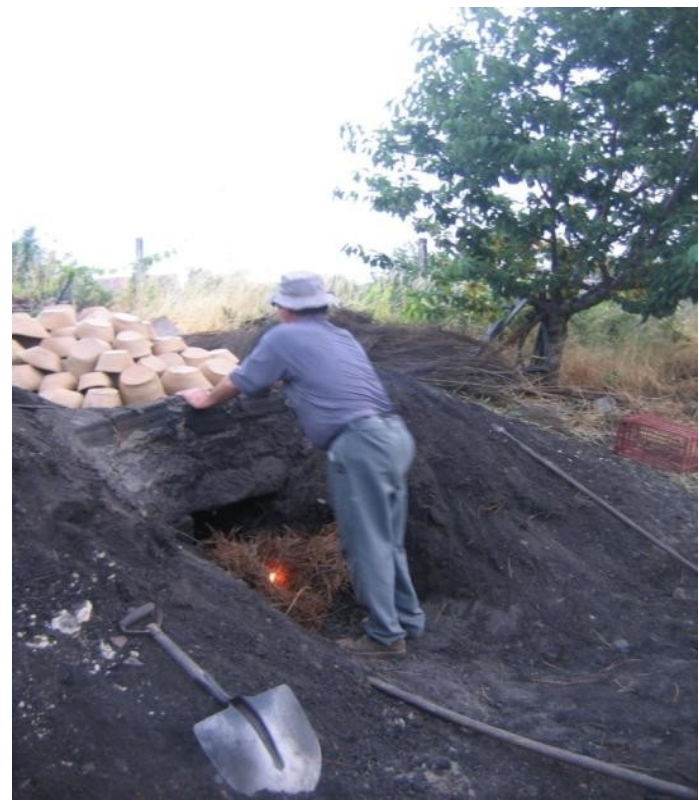

Fig. 6. Sezisnando Ramalho acende o lume do forno. Bisalhães. Fotografia: A. Durand, 24 de Junho de 2006.

Fig. 6. Sezisnando Ramalho lighting his kiln. Bisalhães. Ph. A. Durand June 24th 2006. perto de $12 \mathrm{~m}^{3}$; de seguida, durante cerca de uma hora, lança na fornalha, alternadamente, uma porção de caruma com espécies arbustivas variadas, predominantemente carqueja (Pterospartum tridentatum, Fig. 7). Esta fase da cozedura é importante porque "se o aumento de temperatura é muito alto, a louça parte" (diz o oleiro). O lume arde com as labaredas a elevarem-se a uma altura entre 1,50 a $2,00 \mathrm{~m}$, com a lenha a ser totalmente consumida.

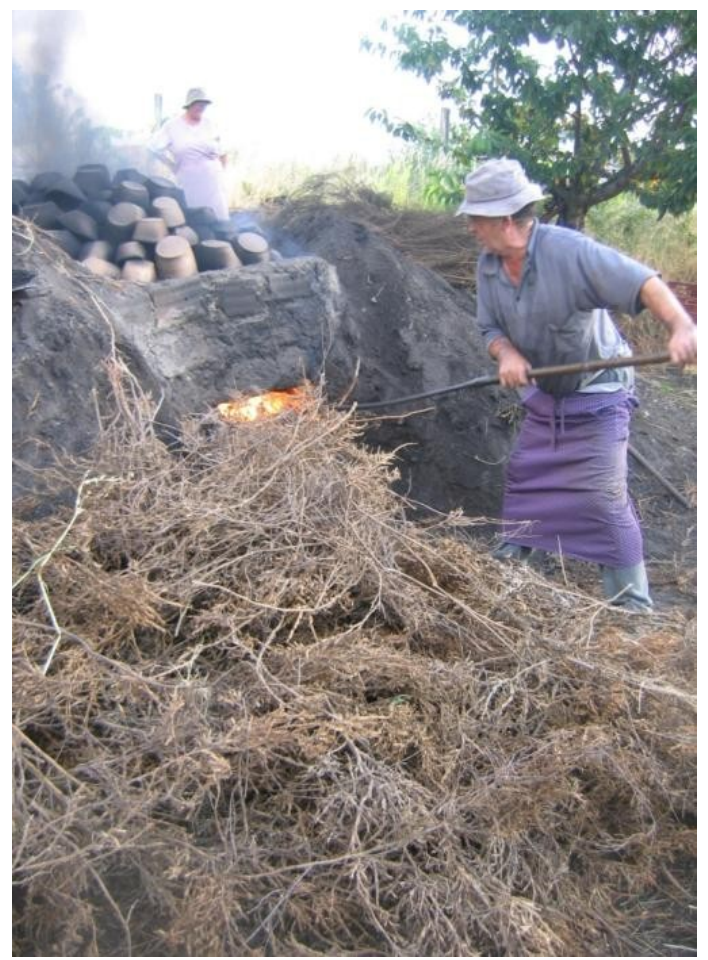

Fig. 7. Após acesso o lume, Sezisnando Ramalho enforna rapidamente o forno com mato. Bisalhães. Fotografia: A Durand, 24 de Junho de 2006.

Fig. 7. Sezisnando Ramalho supplies quickly his kiln with fue just after lighting it. Bisalhães. Ph. A. Durand June 24th 2006.

Durante esse tempo, a mulher do oleiro e a sua ajudante fazem queimar feixes de caruma à volta $\mathrm{e}$ sobre a louça (Fig. 8). Ajudadas pelo oleiro, lançam ramos de pinheiro verdes e secos sobre as peças (Fig. 9). A louça é então envolta em chamas que sobem a uma altura de cerca de $3,00 \mathrm{~m}$ nesta fase da cozedura. Uma quantidade de fumo branco e negro eleva se no ar. Estes dois momentos duram cerca de 12 minutos. A lenha é totalmente consumida, tendo poucas hipóteses de ser arqueologicamente registado. $\mathrm{Na}$ fornalha, o oleiro continua a colocar mato.

Nesta fase, o fogo já não envolve o monte de louça. O forno produz um som particular, ronca. As cerâmicas apresentam uma cor de vermelho sangue específico, vermelho puxado, vermelho tinto ou vermelhinho. Apesar do fumo espesso, os oleiros com enxadas cobrem de terra as peças na totalidade, para abafar. Uma camada de mato é 
colocada em cima para isolar: o processo físicoquímico (pirólise) em atmosfera redutora inicia-se. A boca do forno é cheia com mato, este compactado e a porta encerrada, uma hora e meia depois do início da cozedura. Alguns oleiros vedam a porta com argila, para melhora isolarem. A cozedura redutora demorará algumas horas. O oleiro observa regularmente o forno e o odor que dele sai. Uma hora após ter fechado a porta, alguns oleiros regam com água o monte de terra que cobre a louça: são vertidos quatro regadores de água com intervalos regulares durante meia-hora (Fig 10). Este gesto, também ele, é dificilmente decifrado em arqueologia.

A abertura do forno é efectuada cerca de doze horas depois de se ter iniciado a cozedura da louça. Demora uma hora para retirar 700 peças. Para o arqueólogo, interessa observar o uso dos instrumentos com que tiram a louça ainda quente: longos paus, o ancinho, o ranhão (Fig. 11).

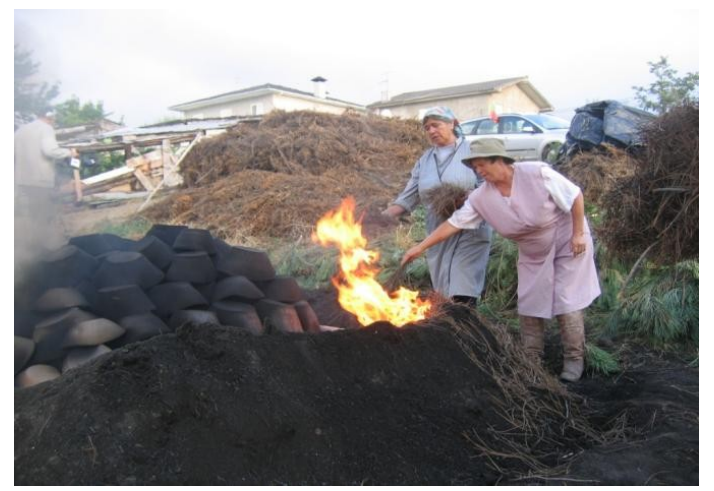

Fig. 8. Noémia Ramalho (mulher do oleiro) e a sua ajudante queimam caruma à volta e sobre a louça. Bisalhães. Fotografia: A. Durand, 24 de Junho de 2006.

Fig. 8. Naomi Ramalho (potter's wife) and her assistant throw pine needles on potteries. Bisalhães. Ph. A. Durand June 24th 2006.

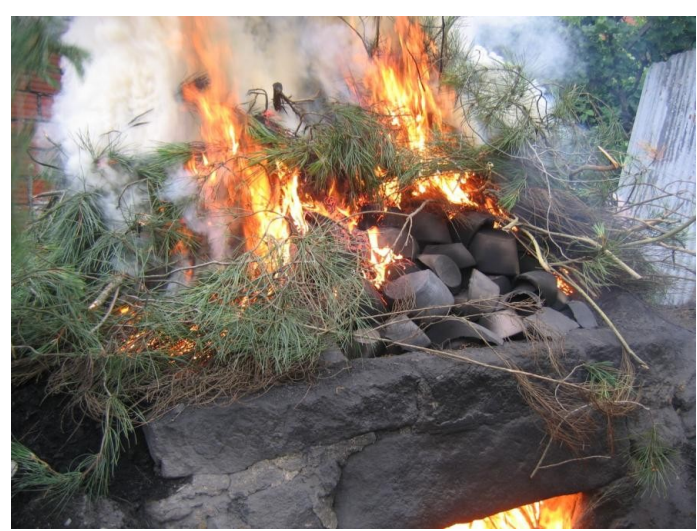

Fig. 9. Ramos de pinheiro verdes são lançados sobre a louça para aumentar a temperatura, antes de fechar a porta do forno. Forno de Cesário da Rocha Martins. Bisalhães. Fotografia: H. Abraços, 20 de Junho de 2007.

Fig. 9. Green branches of pine thrown on potteries to ignite them just before closing the door of the kiln. Kiln of Cesário da Rocha Martins, Bisalhães. Ph. H. Abraços June 24th 2007.

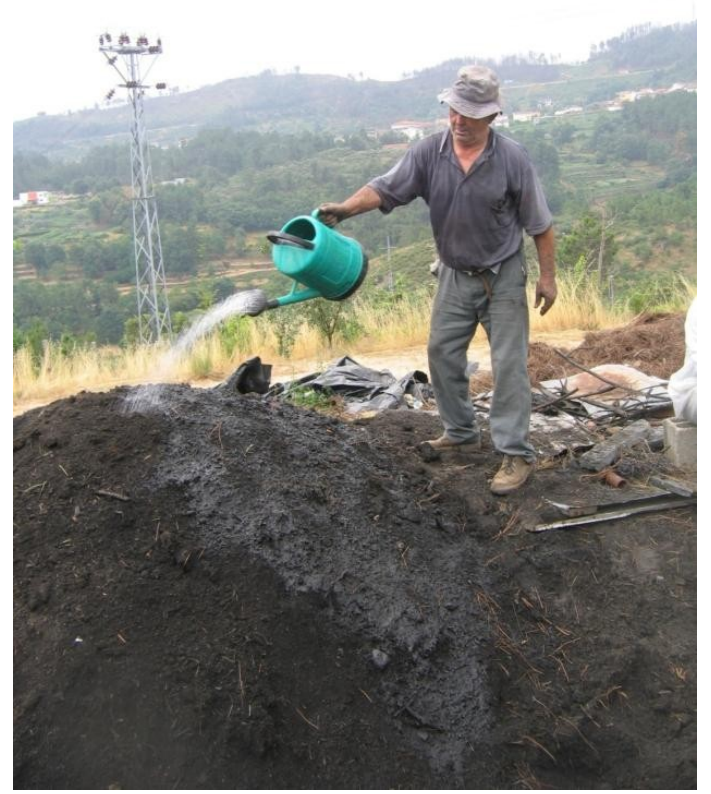

Fig. 10. Depois de fechada a porta do forno, Sezisnando Ramalho rega com água a terra que cobre a louça. Bisalhães. Fotografia: A. Durand, 20 de Junho de 2007

Fig. 10. Sezisnando Ramalho pours a watering can at the top of the kiln once the door of the kiln closed. Bisalhães. Ph. A. Durand June 20th 2007.

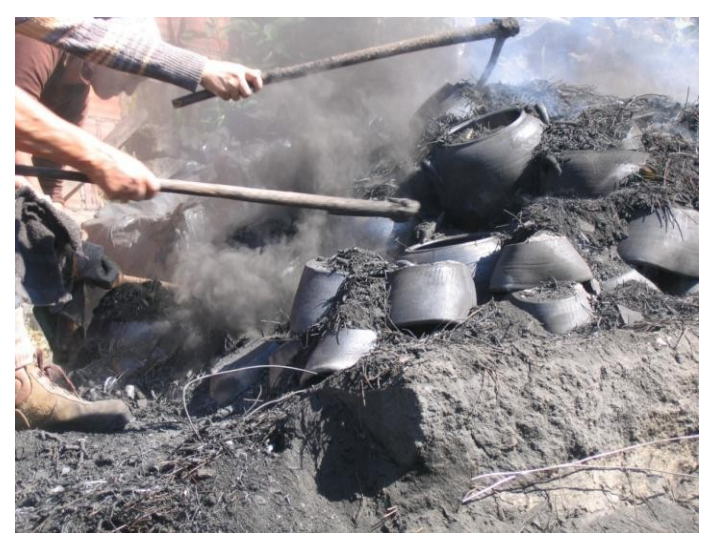

Fig. 11. A louça ainda quente é retirada com a ajuda de um ancinho e um ranhão. Forno de Cesário da Rocha Martins. Bisalhães. Fotografia: A. Durand, 21 de Junho de 2006.

Fig. 11. Kind of hooks made with a pine branch fork used to take hot potteries out of the kiln, kiln of Cesário da Rocha Martins. Bisalhães. Ph. A. Durand June 21 th 2006.

\section{CONCLUSÃO}

O interesse desta investigação é o de ter posto em evidência a presença de informações inexistentes na documentação escrita ou arqueológica, quer sejam materiais (caruma e ramos de pinheiro, água, instrumentos em madeira, transporte improvisado), quer sejam sociais (auxílios de membros da família, ajudas por contrato). É igualmente o de ter ajudado a comentar as observações arqueológi- 
cas e antracológicas, dando relevo ao emprego e uso de lenha de baixo calibre de espessura $(0,1$ $1,5 \mathrm{~cm}$ ) e uma grande abertura do espectro taxinómico. Para obter um aumento rápido da temperatura na cozedura, os oleiros portugueses cortam indiferentemente pequenos pedaços de lenha saídos das matas atlânticas. Não escolhem especificamente este ou aquele tipo de mato, abrindo deste modo o leque de espécies vegetais apanhadas, tal como os resultados das investigações antracológicas obtidas em Saint-Victor-des-Oules (Gard) e em Cabrera d'Anoia (Catalunha) (DURAND 1998 e inédito PY 2001). Este inquérito permitiu também conhecer melhor os volumes de lenha utilizados na cozedura, sem, no entanto, poder quantificá-los.

A análise etnoarqueológica ajuda a compreender os vestígios arqueológicos e antracológicos medievais. Mas também põe em questão interpretações elaboradas pelos investigadores, apresentando respostas em relação "a questões que aos arqueólogos nunca se lhes tinha colocado" (VASCHALDE 2013). Um dos oleiros, conhecido de Jacques Thiriot desde 1986, foi inquirido, como tantos outros, acerca da lenha que utilizava no seu forno. Após ter dado duas respostas consideradas não satisfatórias à questão colocada, acaba por responder: "o que é que eu queimo no meu forno? Tudo o que queima!". Esta resposta é bastante sintomática sobre a percepção do oleiro quanto à lenha usada. As dificuldades geradas sobre as conclusões avançadas pelos antracólogos que estudam os resíduos arqueológicos e tiram conclusões sobre o poder calorífico das substâncias, usadas, sua escolha, etc., fazem-no ter em conta a variabilidade do trabalho do oleiro, a sua adaptabilidade no uso da lenha, alertando contra um excesso de teorização ou de classificação dos tipos de lenha susceptíveis de serem usados. Os inquéritos orais mostraram bem que em período de pressão ou sob certas condições do exercício da arte, o oleiro fazia uso de qualquer lenha ao seu dispor. As observações revelaram igualmente o hiato entre o discurso e a prática, entre a percepção e o saber-fazer, colocando em evidência a variação, mesmo para um só oleiro, dessas práticas.

Essa grande variação, já sublinhada anteriormente (DIOP et al. 2009), é certamente uma das características fundamentais do trabalho dos oleiros. É preciso guardar registo para memória futura, como orientação para encorajar e enriquecer os estudos arqueológicos sobre este tipo de fornos.

\section{BIBLIOGRAFIA}

ABraÇOS, H; \& THIRIOT, J. 2003. Les traces des potiers Valverde à l'épreuve des taupes. In: H. Abraços, J. Diogo (Coord.), 3. ${ }^{\text {as }}$ Jornadas de Cerâmica Medieval e Pós-Medieval. Métodos e resultados para o seu estudo. (Tondela 1997), Tondela, Câmara Municipal de Tondela: 311-319.

CAMPos, M. \& CARVAlHO, D. 1999. Bisalhães - anatomia de um povo. Centro Cultural Regional de Vila Real.
BazzanA, A. \& Delaigue, M.-CH. 1995. In: A. Bazzana M. Delaigue (Dir.), Ethnoarchéologie méditerranéenne: finalités, démarches, résultats, ParisMadrid, Casa de Velázquez, C.N.R.S

BINFORD, L. 1978. Nunamuit Ethnoarchaeology, New YorkLondon-San Francisco, Academic Press.

BuCAILle, R. \& Pesez, J.-M. 1980. L'habitat paysan en Bourgogne viticole du XIVe au XIXe siècle: approche anthropologique. Archeologia medievale, 7: 73-82.

CAndeias, A. 1931. A industria doméstica da louça preta de Bisalhães. Revista Lusitana, 29, n. ${ }^{\text {os }}$ 1-4: 301-306.

CoIMBra 1948. Louça preta de Molelos. Mensário das Casas do Povo, Ano II, n 22, Abr.: 12-13.

Correia, A. 1980. O último oleiro de Fazamões. Beira Alta, Viseu, 1. ${ }^{\circ}$ e 2. trimestre, 241-275.

Diop, B; Thiriot, J.; Diogo, J. \& CAFÉ, R. 2008. Regards ethnographiques sur le façonnage des assadeiras en louça preta du centre et nord du Portugal. In: J. Diogo (Coord.), $4 .^{\text {as }}$ Jornadas de Cerâmica Medieval e Pós-Medieval. Métodos e resultados para o seu estudo. (Tondela 2000), Tondela, Câmara Municipal de Tondela: 383-397.

DURAND, A. 1998. Les paysages médiévaux du Languedoc (Xe-XIIe siècles), Toulouse, Presses Universitaires du Mirail.

GALLAY, A. 1980. Réflexion sur le concept d'ethnoarchéologie. Les nouvelles de l'archéologie, 4: 34-42.

GAllay, A. \& HuYSECOM, E. 1989. Ethnoarchéologie africaine, un programme d'étude de la céramique récente du Delta intérieur du Niger (Mali, Afrique de l'Ouest), Département d'anthropologie et d'écologie de l'université de Genève, Document 14.

Gallay, A. 2000. Peuplement et histoire de la boucle du Niger (Mali): un exemple de recomposition sociale dans l'artisanat du feu. In: P. Petrequin, P, Fluzin, J. Thiriot, P. Benoit, (Edit). Arts du feu et productions artisanales. Actes des XXe rencontres internationales d'archéologie et d'histoire d'Antibes (21-23 oct. 1999), Antibes, APDCA: 237-259.

Gallay, A. 2011. Pour une ethnoarchéologie théorique. Mérites et limites de l'analogie ethnographique, Arles, Actes Sud.

Leroi-Gourhan, A. \& Brezillon, M. 1972. Fouilles de Pincevent: essai d'analyse ethnographique d'un habitat magdalénien, Paris, CNRS, 7e supplément à Gallia-Préhistoire.

PiCon, M.; ThIRIOT, J.; ABRAÇOS, H. \& Diogo, J 1995 Estudo em laboratório e observação etnoarqueológica das cerâmicas negras portuguesas. In: H. Abraços, J. Diogo (Org.), $1^{a s}$ Jornadas de Cerâmica Medieval e Pós-Medieval. Métodos e resultados para o seu estudo. (Tondela 1992), Tondela, Câmara Municipal de Tondela: 189-206.

PoIsson, J. M. 2003a. La maison rurale médiévale en Sardaigne : un atelier d'ethno-archéologie. In: The rural house from the migration period to the oldest still standing buildings. Actes du colloque Ruralia IV (Berderkesa 2001), Památky Archeologické, supplementum 15: 232-239.

Poisson, J. M. 2003b. Aux confins de l'archéologie et de l'ethnographie: recherches dans le Bois de SaintGuinefort (Ain). In: Textes et images pour Jean Guibal, Grenoble, Patrimoine en Isère, hors-série, Centre alpin et rhodanien: 215-220. 
PY, V. 2001. Les potiers et la forêt à Cabrera d'Anoia (Catalogne): XIIe-XIVe siècles. Anthracologie, ethnobotanique et paléoécologie, archéologie et artisanat, maîtrise d'archéologie, Université d'AixMarseille I.

RIBEIRO, O. 1987. Mediterrâneo. Ambiente e tradição. $2^{\mathrm{a}}$ edição, Lisboa, Fundação Calouste Gulbenkian.

THEMUdo, F. 1905. Estudo sobre o estado actual da industria ceramica na $2{ }^{a}$ circumscripção dos serviços technicos da industria. Ministerio das Obras Publicas, Commercio e Industria, Lisboa, Imprensa nacional: $155-162$.

THIRIOT, J. 1986. Les ateliers médiévaux de poterie grise en Uzège et dans le bas-Rhône. Premières recherches de terrain, Paris, Maison des Sciences de l'Homme, Documents d'Archéologie française, 7.

Thiriot, J.; ABraços, H. \& Diogo, J. 1992. A olaria negra em Portugal, ontem e hoje: urgência no seu estudo. In: Arqueologia Medieval, Campo Arqueológico de Mértola. Porto, Edições Afrontamento, 1:179-188.
THIRIOT, J. 2004. Les ateliers de potiers médiévaux en Méditerranée: approches archéologiques occidentales, ethnoarchéologie et comparaisons orientales, Habilitation à Diriger les Recherches en archéologie, Université d'Aix-Marseille I, 3 vols.

THIRIOT, J. 2013. De l'utilité de l'ethnoarchéologie, de l'archéologie expérimentale et de l'ethnoarchéométrie dans l'étude des ateliers médiévaux à poterie noire. In: B. SZMONIEEWSKI (éd.), Archéologie, Paris, 2013, Numéro spécial des Annales de l'Académie polonaise des sciences, Varsovie-Paris, Centre Scientifique à Paris (vol. 8): 200-248.

VASCHALDE, Ch. 2013. L'art de cuire la pierre en France méditerranéenne à la fin du Moyen Âge. Approche interdisciplinaire d'un artisanat méconnu: la chaufournerie, thèse de l'université d'Aix-Marseille, 3 vols

Villas-BoAs, J. SEllÉs PAES de. 1942. Notas de cerâmica popular II. O centro oleiro de Vilar-de-Nantes. In Ethnos, Revista do Instituto Português de Arqueologia, História e Etnografia, vol. II, Lisboa: 348-359. 